\title{
MANAS DESTANINDA (S. OROZBAKOV) ÇAĞDAŞ TÜRK LEHÇELERINE ÖZGÜ GRAMER ÖZELLİKLERİ
}

Nurdin USEEV

\begin{abstract}
Özet
Dünyanın en büyük destanı olarak bilinen Manas Destanı, Kırgızların millî kimliğini oluşturmada çok önemli bir rol oynayan kültürel olgudur. Çünkü söz konusu destan halkın tarihini, kültürünü, dünya görüşünü, halkın millî seviyedeki amaçlarını yansıtan bir eserdir. Özellikle Eski Türk kültürünü yansıtması açısından bilim adamları tarafından bir ansiklopedi olarak değerlendirilmiştir. Üstelik, S. Orozbakov varyantında Manas'ın diline Türkü til, Türkçe denilmektedir. Yani söz konusu destanın Türklüğün ortak kültürel mirası olduğu vurgulanmıştır. Bu bağlamda Manas Destanında Kırgızlara komşu Türk topluluklarının dil özelliklerinin bulunması beklenmektedir. Gerçekten de Manas Destanında Kazak, Özbek Türkçesine ait bazı gramer özelliklerinin yer aldığı tesbit edilmiştir. Örneğin, Manas Destanında şimdiki zaman için Kazak Türkçesine özgün olan -Xr eki kullanılmaktadır.
\end{abstract}

Anahtar Kelimeler: Manas Destanı, Çağdaş Türk Lehçeleri, Türk halkları, Kazak Türkçesi, Gramer Özellikleri.

\section{GRAMMAR FEATURES OF CONTEMPORARY TURKISH DIALECTS IN MANAS EPIC}

\begin{abstract}
The Manas epic, known as the world's greatest epic, is a cultural phenomenon that plays a crucial role in creating the Kyrgyz national identity. Because this epic is a work that reflects the history of the people, the culture, the world view, the aims of the people at the national level. It has been regarded as an encyclopedia by scientists in terms of reflecting the ancient Turkish culture in particular. Moreover, in S. Orozbakov's variant, the language of Manas is called Turkic til, Turkish. In other words, it was emphasized that the epic is a common cultural heritage of Turkic world. In this context, it is expected that the language characteristics of Turkic nations neighboring Kyrgyz are expected to be found in Manas Epic. Indeed, it has been found that some grammatical features of the Kazakh, Uzbek Turkic languages are included in the Manas Epic. For example, in the epic of Manas, is used suffix - $\mathrm{Xr}$ for the present time which is unique to Kazakh language.
\end{abstract}

Key Words: Manas Epic, Contemporary Turkish Dialects, Turkish Peoples, Kazakh Turkish, Grammatical Features.

\section{Giriş}

Ö. Çobanoğlu tarafından "Türk epik destan geleneği evreninin kutup yıldızı olan Oğuz Kağan Destanını yeryüzüne ve bugüne bağlayan altın kazık" olarak değerlendirilen (2017: 13) Manas Destanının dili de ayrı bir önem arz etmektedir. Çünkü Manas Destanının dili Kırgız Türkçesinin tarihî devrelerinin özelliklerini içinde barındıran ve XIX. yüzyıldaki Kırgızların tamamının dilini yansıtan bir destandır (Oruzbaeva, 2004: 165-167). Üstelik, Manas Destanının S. Orozbakov varyantında destanın, destan kahramanlarının diline Türküçö, Türkü til, Türki til, Türk til, Türktün tili, Türkünün tili denilerek söz konusu destanın sadece Kırgız Türklerinin

\footnotetext{
* Yrd. Doç. Dr., Kırgızistan-Türkiye Manas Üniversitesi, Edebiyat Fakültesi, Türkoloji Bölümü, KIRGIZISTAN, el-mek: nuruseev@mail.ru
} 
değil, bütün Türk boy ve topluluklarının tarihini, kültürünü, inancını ve millî kimlik duygusunu kapsayan bir ansiklopedi özelliği taşıyan bir eser olduğunu göstermektedir (Useev, 2016a: 204, 222).

Destanın metninde Çağdaş Kırgız Türkçesinin edebî dilinde bulunmayan bazı dil özelliklerinin bulunduğu hemen göze çarpmaktadır. Bu özelliklerin bir kısmı arkaik unsurlardır. Örneğin, Manas Destanının Cusup Mamay variyantındaki arkaik kelimeleri ele alan M. Rakımbek Uulu'nun doktora tezinde 1000'e yakın arkaik kelime tespit edilmiştir (Rakımbek Uulu, 2010). Bazı özellikler de tarihî Türk lehçelerine aittir. Mesela, tarihî Türk lehçelerinde güç, kuvvet, güzel anlamında geçen türk kelimesi bugünlerde sadece Manas Destanında büyük, güzel anlamlarında varlığını korumuştur (Useev, 2016b, Useev, 2017). Manas Destanındaki Kırgız Türkçesinin edebî dilinden farklılık gösteren dil özelliklerinin bir kısmı ise Kırgız Türkçesinin ağızları aracılığıyla ya da doğrudan çağdaş Türk lehçelerinden edinilen özelliklerdir. Makalemizde işte bu özellikler ele alınmıştır.

\section{1. Şimdiki Zaman -Xr Eki}

Kırgız Türkçesi ile ilgili çalışmalarda şimdiki zaman basit şimdiki zaman ve birleşik şimdiki zaman olarak ikiye ayrılır. Basit birleşik zaman asıl fiile ya da cat-, cür-, otur-, turyardımc fiillerine -X zarf fiil ekinin getirilmesi ile yapılır: Eki cigit çaldın eki cagında otur-a-t (Ikki yiğit ihtiyarın iki yanında oturuyorlar) (A. Tokombaev); Şaarda tur+a+m (Şehirde oturuyorum) (Kudaybergenov vd., 1980: 387-388). Birleşik şimdiki zaman asıl fiile -Xp, -X zarf-fiil eklerinin, cat-, cür-, otur-, tur- yardımc1 fiillerine $\mathbf{- X}$ zarf-fiil ekinin getirilmesi ile yapılır: Men kubanıçımdan caş-ıp oltur-a-m (Ben sevincimden ağllyorum) (A. Tokombaev); terezeden biröö kar-ap tur-a-t (Camdan birisi bakiyor) (M. Elebaev) (Kudaybergenov vd., 1980: 392-393). Manas Destanında da şimdiki zaman bu şekillerde yapılmıştır:

\begin{tabular}{|c|c|}
\hline \multicolumn{2}{|c|}{ S. Orozbakov, I. kitap, s. 324-325, 8138-8143. satırlar } \\
\hline $\begin{array}{l}\text { Manas Destanı (Özgün } \\
\text { Metin) }\end{array}$ & $\begin{array}{l}\text { Türkiye Türkçesine } \\
\text { Aktarımı }\end{array}$ \\
\hline Tizelerin tayanıp, & Dizlerine dayanıp, \\
\hline Tiktep cerge karaşat, & Yere baklyorlar, \\
\hline Başın cerge eki urup, & Başlarını yere iki vurup, \\
\hline Baarı koop tik turup, & Hepsi kalkıp dik durup, \\
\hline Kün batışka karaşıp, & Gün batısına bakarak, \\
\hline Kübüröşüp kalışat, & İçlerinden konuşuyorlar \\
\hline \multicolumn{2}{|c|}{ S. Orozbakov, II. kitap, s. 260, 11440-11442. satırlar } \\
\hline $\begin{array}{l}\text { Manas Destanı (Özgün } \\
\text { Metin) }\end{array}$ & $\begin{array}{l}\text { Türkiye Türkçesine } \\
\text { Aktarımı }\end{array}$ \\
\hline Közü calın canganday, & Gözü ateş yanar gibi, \\
\hline Kele catat bu kaapır, & Geliyor bu kafir, \\
\hline Kaçırıp kaman çalganday. & Saldırmış domuz gibi. \\
\hline
\end{tabular}

Destanda hem birleşik şimdiki zaman, hem de sıradan şimdiki zaman için Kırgız Türkçesine özgün olan şekilden başka -Xr şeklindeki farklı bir ek de kullanılmaktadır: 


\begin{tabular}{|c|c|}
\hline \multicolumn{2}{|c|}{ S. Orozbakov, I. kitap, s. 85, 92-95. satırlar } \\
\hline $\begin{array}{l}\text { Manas Destanı (Özgün } \\
\text { Metin) }\end{array}$ & $\begin{array}{l}\text { Türkiye Türkçesine } \\
\text { Aktarımı }\end{array}$ \\
\hline Esi cok kanday katınsıy, & Aklı yok nasıl kadınsın, \\
\hline Esirgen kanday kaapırsın? & Kin taşıyan nasıl kafirsin? \\
\hline Erteli keçti men çıksam & Sabah ve akşam ben çıksam \\
\hline Elkim üydö catırsıy & Serbest evde yattyorsun \\
\hline \multicolumn{2}{|c|}{ S. Orozbakov, I. kitap, s. 311, 7624-7625. satırlar } \\
\hline $\begin{array}{l}\text { Manas Destanı (Özgün } \\
\text { Metin) }\end{array}$ & $\begin{array}{l}\text { Türkiye Türkçesine } \\
\text { Aktarımı }\end{array}$ \\
\hline Özgöçö külük Çabdar at & Çok yürük Çabdar at \\
\hline Öksütüp ketip baratır, & Mesafeyi azaltarak geliyor \\
\hline \multicolumn{2}{|c|}{ S. Orozbakov, II. kitap, s. 181, 7740-7742. satırlar } \\
\hline $\begin{array}{l}\text { Manas Destanı (Özgün } \\
\text { Metin) }\end{array}$ & $\begin{array}{l}\text { Türkiye Türkçesine } \\
\text { Aktarımı }\end{array}$ \\
\hline Dagalak curtu baarınar, & Dagalak halkı hepiniz \\
\hline Körüp tursuy közümdü, & Görüyorsunuz gözümü, \\
\hline Ugup tursuy sözümdü, & Dinliyorsunuz sözümü, \\
\hline
\end{tabular}

T. Şarşenbek Uulu, Manas Destanındaki ağız özelliklerini ele alan çalışmasında bu eki morfolojik ağız özelliği olarak değerlendirmiştir. Çünkü söz konusu ek Kırgız Türkçesinin Çatkal, Talas, Çüy, Celal-Abad govorlorunda bir ağız özelliği olarak geçmektedir (2014: 53). Gerçekten -Xr şeklindeki şimdiki zaman eki Kırgız Türkçesinin Talas govorunda çok kullanılmaktadır (Abduldaev, 1966: 62). Talas govorunun konuşulduğu Talas İl'i coğrafik bakımından Kazakistan'a yakın olduğu için söz konusu govorun birçok özelliği Kazak Türkçesinden etkilenmiş dil özellikleridir. Kazak Türkçesinde ise şimdiki zaman -Xr eki ile yapılmaktadır: Ol hat cazıp otır (O mektup yazıyor) (Balakaev vd., 1962: 337). Aynı ek Hakas Türkçesinde de şimdiki zaman eki olarak kullanılır (Arıkoğlu, KTLG, 2006: 338). Destanın I. kitabının Giriş bölümünü yazan R.Z. Kıdırbaeva, Manas Destanında şimdiki zaman için Kazak Türkçesine özgün olan -Xr ekinin kullanıldığına dikkat çekerek şunları belirtmektedir: manasçıların 'baratır' fiilini kullanması sadece destanda gözükür. Misraların kafiyesini sağlamak için de kullanılmıyor. Sadece söylenmekte olan metnin anlamına göre kullanılır. Örneğin, Kırgız, Kazakların Kalmuklara yaptığı saldırılar anlatılırken çok söylenir (S. Orozbakov, I.kitap, s. 10). Demek ki söz konusu ek destanda sadece stilistik amaçla değil, metnin içeriğine göre de geçerek Kırgızlar ile Kazakların düşmanlara karşı birlikte savaştıklarını yansıtmaktadır. Dolayısıyla destanda şimdiki zaman için bazen -Xr ekinin kullanılmasını hem ağız özelliği, hem de Kazak Türkçesinin etkisi olarak değerlendirebiliriz.

\section{2. Şimdiki Zaman -dX Eki}

Türk dilinde şimdiki zaman yapan tur- yardımcı fiili Kırgız Türkçesinde, III. şahısta artık ekleşmiştir: Kez-kez brigadirdin bakıldagan ünü ugul-at (Bazen brigadirin (çalışanlara bakan kişi) yüksek sesi duyuluyor) (N.Baytemirov) (Kudaybergenov vd., 1980: 387). Manas Destanında da şimdiki zamanın III. şahıs çekimi bu şekildedir: 


\begin{tabular}{||c|c|}
\hline \multicolumn{2}{|c|}{ S. Orozbakov, III. kitap, s. 274, 12907-12909. satırlar } \\
\hline $\begin{array}{c}\text { Manas Destanı (Özgün } \\
\text { Metin) }\end{array}$ & Türkiye Türkçesine Aktarımı \\
\hline Katın-bala çırkırap, & Kadın-çocuk gürültü yapıp \\
Kaçıp barat kaapırlar & ağlayıp, \\
Kök-Adırda çurkurap. & Kaçıp gidiyorlar kafirler \\
& Kök-Adır'da gürültü yapıp \\
\hline S. Orozbakov, VI. kitap, s. 106, 3525-3528. satırlar
\end{tabular}

Bununla birlikte Manas Destanında şimdiki zamanın III. şahıs çekiminin -adı, -edi, (y)di, -(y)dı şeklindeki, Kırgız Türkçesine özgün olmayan türü de bulunmaktadır:

\begin{tabular}{|c|c|}
\hline \multicolumn{2}{|c|}{ S. Orozbakov, I. kitap, s. 108, 738-741. satırlar } \\
\hline $\begin{array}{l}\text { Manas Destanı (Özgün } \\
\text { Metin) }\end{array}$ & $\begin{array}{l}\text { Türkiye Türkçesine } \\
\text { Aktarımı }\end{array}$ \\
\hline $\begin{array}{l}\text { Arıtıp Cakıp karadı, } \\
\text { Ak-Ötök degen aralga, } \\
\text { Arasında kara suu, } \\
\text { Attatıp ötüp baradı. }\end{array}$ & $\begin{array}{c}\text { Uză̆a Cakıp baktı, } \\
\text { Ak-Ötök adlı adaya, } \\
\text { Ortasında kara su (küçük } \\
\text { nehir), } \\
\text { Atlatıp geçip gidiyor }\end{array}$ \\
\hline \multicolumn{2}{|c|}{ S. Orozbakov, IV. kitap, s. 285, 12960-12964. satırlar } \\
\hline $\begin{array}{l}\text { Manas Destanı (Özgün } \\
\text { Metin) }\end{array}$ & $\begin{array}{l}\text { Türkiye Türkçesine } \\
\text { Aktarımı }\end{array}$ \\
\hline $\begin{array}{l}\text { Toskongo Bakay turabı, } \\
\text { Kalgan nayzasına da } \\
\text { Cana kılıç uradı, } \\
\text { Aliginin nayzası } \\
\text { Altı bölünüp turadı. }\end{array}$ & $\begin{array}{l}\text { Korunduğuna Bakay bakar } \\
\text { Să̆ kalan mızrağına da } \\
\text { Yine kılıç vuruyor, } \\
\text { Obürünün mızră̆ı } \\
\text { Altıya kırılıp kalıyor. }\end{array}$ \\
\hline
\end{tabular}


Gördüğümüz gibi destanda şimdiki zamanın III. şahıs çekiminin -adı, -edi, -(y)di, (y)dı şekli birçok yerde geçmektedir. Söz konusu ek Kazak, Özbek, Uygur, Karaçay-Malkar Türkçelerinde aktiv bir şekilde kullanılan çekim ekidir (KTLG, 2006: 129-131, 134). Dolayısıyla -adı, -edi, -(y)di, -(y)dı ekini genel Türk dili özelliği olarak ele alabiliriz. Çünkü bu ek Kırgız Türkçesinde kullanılmayıp başka Türk lehçelerine ait olan ve sadece Manas Destanında geçen bir ektir.

\section{3. +nI Yükleme Hali Eki}

Kırgız Türkçesinde yükleme hali III. teklik ve çokluk şahıs iyelik ekinden sonra +n şeklinde gelir: at $+\mathbf{I}+\mathbf{n}$ (adını), till+i+n (dilini), ata $+\mathbf{s i}+\mathbf{n}$ (babasını), ini+si+n (kardeşini), kız+darı+n (kızlarını), ata+ları+n (babalarını) (Kasapoğlu Çengel, 2005: 168, Kudaybergenov $v d$., 1980: 191). Ancak destanın birçok yerinde yükleme hali eki III. şahıs teklik ve çokluk iyelik ekinden sonra yukarıda anlatılandan farklı olarak $\mathbf{n} \mathbf{X}$ eki ile yapıldığ görülmektedir:

\begin{tabular}{|c|c|}
\hline \multicolumn{2}{|c|}{ S. Orozbakov, I. kitap, s. 98-99, 475-478. satırlar } \\
\hline $\begin{array}{l}\text { Manas Destanı (Özgün } \\
\text { Metin) }\end{array}$ & $\begin{array}{l}\text { Türkiye Türkçesine } \\
\text { Aktarımı }\end{array}$ \\
\hline Bay Cakıp ayttı tüşünü & Bay Cakıp anlattı rüyasını, \\
\hline Baybiçe bildi uşunu. & Hanımı bildi şunu. \\
\hline 'Kondurat eken kudayım & 'Konduracakmış Tanrım \\
\hline Başı̀a döölöt kuşunu'. & Başına devlet kuşunu'. \\
\hline \multicolumn{2}{|c|}{ S. Orozbakov, IX. kitap, s. 678, 2984-2987. satırlar } \\
\hline $\begin{array}{l}\text { Manas Destanı (Özgün } \\
\text { Metin) }\end{array}$ & $\begin{array}{l}\text { Türkiye Türkçesine } \\
\text { Aktarımı }\end{array}$ \\
\hline Raatir Rokav ciountur & Baatır Bakay yere yıkmış \\
\hline Küşkö kandın tuusunu, & Küşkö Han'ın bayrağını, \\
\hline Adam uulu körbösün & İnsan oğlu görmesin \\
\hline Keseliktin çuusunu. & $\begin{array}{l}\text { Keselik'in gürültü ve } \\
\text { kötülüğ̈̈nü }\end{array}$ \\
\hline
\end{tabular}

Kırgız Türkçesinin ağız çalışmalarında yükleme halinin III. teklik ve çokluk şahıs iyelik ekinden sonra +nX şeklinde olması Kırgız Türkçesinin Güney ağızlarının bir özelliği olarak değerlendirilir (Abduldaev, 1966: 40). Bununla birlikte III. teklik ve çokluk şahıs iyelik ekinden sonra +nX ekinin kullanılması Türkiye Türkçesi, Azeri Türkçesi ve başka Türk lehçelerine özgündür. Örneğin, yükleme hali eki Özbek Türkçesinde hep +nI eki ile yapılır (Buran ve Alkaya, 1999: 141). Kırgız Türkçesinin Güney ağızları ise sınırdaş olduğu için Özbek Türkçesinden etkilenmiştir. Ancak destandaki yükleme hali eki ile ilgili bu özelliği, yani $+\mathbf{n X}$ ekinin kullanılmasını başka bir Türk lehçesinden etkilenmiş ağız özelliği olarak nitelendirmek doğru, fakat yeterli değildir. Çünkü, Orta Asya'daki Karhanlıca, Harezm Türkçesi, Kıpçakça, Çağatayca gibi tarihî Türk lehçelerinde $+\mathbf{n X}$ yükleme hali ekinin yanında $+\mathbf{n}$ eki de kullanılmıştır. J. Eckmann Harezm Türkçesi ile Çağatayca'da III. şahıs iyelik ekinden sonra +nI veya $+\mathbf{n}$ yükleme hali eklerinin kullanıldığını belirtmektedir: yol $+\mathbf{l}+\mathbf{n} \mathbf{n} / \mathbf{y o l}+\mathbf{+}+\mathbf{n}$ (yolunu), $\mathbf{a n a}+\mathbf{s} \mathbf{+}+\mathbf{n} \mathbf{~ ( a n n e s i n i ) , ~} \mathbf{k o ̈ z}+\mathbf{i}+\mathbf{n i} / \mathbf{k o ̈ z}+\mathbf{i}+\mathbf{n}$ (gözünü) (Eckmann, 2003: 15, 120) Bize göre destanda III. şahıs iyelik ekinden sonra hem $+\mathbf{n I}$, hem de $+\mathbf{n}$ yükleme hali eklerinin kullanılması işte bu tarihî Türk lehçelerindeki özelliğin devamı da olabilir. 


\section{4. men Bağlacı}

Kırgız Türkçesinde cümle içindeki iki kelimeyi bağlamak için ile, ve anlamında menen bağlaçı kullanılır: Anın artınan cabalaktap kele catkan mayda köçtör Tülkübek menen Atabektin işin kılgan malaylardıkı cana kara küçün cumşap bekterdin közün karagan beçara saançılardık1 (Onun arkasından gelmekte olan çok sayıdaki küçük göçler Tülkübek ile Atabek'in işini yapan hizmetçilerinki ve işini-gücünü vererek beylerin eline bakan sefil sütçülerinkidir) (K.Cantöşev) (Kudaybergenov vd., 1980: 500, 504). Manas Destanında bu bağlaç genellikle hiçbir değişikliğe uğramadan kullanılmakla birlikte bir kaç yerde men şeklinde geçmektedir:

\begin{tabular}{||c|c||}
\hline \multicolumn{2}{|c|}{ S. Orozbakov, V. kitap, s. 46, 1019-1021. satırlar } \\
\hline $\begin{array}{c}\text { Manas Destanı (Özgün } \\
\text { Metin) }\end{array}$ & $\begin{array}{c}\text { Türkiye Türkçesine } \\
\text { Aktarımı }\end{array}$ \\
\hline Askeri arbın, kolu köp, & Askeri çok, ordusu fazla, \\
Kolgo kelgen adamdan & Orduya gelen insandan \\
Körünbödü cer men kök. & Görümedi yer ile gök \\
\hline
\end{tabular}

Görüldüğü gibi yukarıdaki mısralarda menen bağlacının sonundaki en hecesi kısalmış şekli geçmektedir. Bunun nedeni menen bağlacının/edatının Kazak Türkçesindeki kullanım özelliğidir. Bilindiği gibi Eski Türkçede birlen/birle şeklinde olan söz konusu bağlaç/edat Eski Kıpçak Türkçesinin dağılmasından sonra Kıpçak grubuna giren lehçelerde, özellikle Kazak Türkçesinde men, pen, ben şeklinde kısalmıştır: Küymege minetin Uljan men Kalika gana (Faytona binecekler sadece Uljan ve Kalikadl) (M. Avezov) (Balakaev vd., 1962: 405; Tenișev vd., 2002: 309). Manas Destanındaki men bağlacını Kazak Türkçesinden etkilenmiş bir değişiklik olarak ele alıp, genel Türk dili özelliği sayabiliriz.

\section{Sender Zamiri}

Kırgız Türkçesinde çokluk II. şahıs zamiri siler, sizler şeklindedir. Yani eski si ve yeni siz köklerine -IAr çokluk ekinin getirilmesi ile yapılır (Kudaybergenov vd., 1980: 254). Manas Destanında, birkaç yerde çokluk II. şahıs zamiri yukarıdakilerden farklı biçimde, sender biçiminde geçmektedir:

\begin{tabular}{||c|c||}
\hline \multicolumn{2}{||c||}{ S. Orozbakov, II. kitap, s. 98-99, 5797-5800. satırlar } \\
\hline $\begin{array}{c}\text { Manas Destanı (Özgün } \\
\text { Metin) }\end{array}$ & $\begin{array}{c}\text { Türkiye Türkçesine } \\
\text { Aktarımı }\end{array}$ \\
\hline Altın, kümüş, zumurat & Altın, gümüss, zümrut \\
Kolundagı bul - dedi, & $\begin{array}{c}\text { Elindeki para dedi, } \\
\text { Bir caratkan kudayga }\end{array}$ \\
Senderden beter kul - dedi. & Sizlerden beter köle dedi \\
\hline \multicolumn{2}{|c|}{ S. Orozbakov, IV. kitap, s. 225, 10059-10062. satırlar } \\
\hline Manas Destanı (Özgün \\
Metin)
\end{tabular}




\begin{tabular}{||l|c||}
\hline \hline $\begin{array}{l}\text { Dajgittan kelgen el barb1, } \\
\text { Tayşuudan kelgen er barbı? }\end{array}$ & $\begin{array}{c}\text { Daygittan gelen halk var mı, } \\
\text { Tajşuudan gelen er var mı? }\end{array}$ \\
\hline
\end{tabular}

Yukarıdaki mısralarda geçen ve Kırgız Türkçesine özgün olmayan sender kişi zamiri Kıpçak Türkçesinde, özellikle Kazak Türkçesinde yaygın kullanılan zamirdir (Buran ve Alkaya, 1999: 283). Demek ki Kazak Türkçesine has olan sender kişi zamirinin geçmesi Manas Destanın dilinin Kırgız Türkçesinden başka çağdaş Türk lehçelerinin bazı özelliklerini barındırdığını kanıtlamaktadır.

\section{Yönelme Halinin I. ve II. şahıstaki Magan, Sagan Çekimleri}

Kırgız Türkçesinde yönelme hali -GA eki ile yapılarak men, sen, al şahıs zamirleri maga, saga, aga şeklinde çekimlenir (Kudaybergenov vd., 1980: 199, 262). Bundan dolay1 Manas Destanında men, sen şahıs zamirleri yönelme halinde maga, saga olarak çekimlenmiştir. Ancak destanının birkaç yerinde söz konusu şahıs zamirleri magan ve sagan şeklinde geçmektedir:

\begin{tabular}{|c|c||}
\hline \multicolumn{2}{|c|}{ S. Orozbakov, V. kitap, s. 432, 16540-16544. satırlar } \\
\hline $\begin{array}{c}\text { Manas Destanı (Özgün } \\
\text { Metin) }\end{array}$ & $\begin{array}{c}\text { Türkiye Türkçesine } \\
\text { Aktarımı }\end{array}$ \\
\hline 'Aytkanı öttü magan dep, & Söylediği bana dokundu diye, \\
Akılın kılgın balam dep, & Söylediğini yap çocuğum diye, \\
Alooke aman bar tursa, & Alooke să̆ olursa, \\
Altayga kayra baram' dep, & Altay'a yine gideceğim diye, \\
Aytıp turdu Cakıp bay, & Söyleyip durdu Cakıp bay, \\
\hline \multicolumn{2}{|c||}{ S. Orozbakov, VI. kitap, s. 50, 1332-1336. satırlar } \\
\hline Manas Destanı (Özgün \\
Metin)
\end{tabular}

Ben, sen şahıs zamirlerinin Kırgız Türkçesine mahsus olmayan magan ve sagan şekilleri Manas Destanında Kazak Türkçesinin tesiri ile kullanılmıştır. Çünkü Kazak Türkçesinde teklik şahıs zamirleri (men, sen, ol) yönelme halinde magan, sagan, ogan şeklinde çekimlenmektedir (Kaydarov, 1997: 251). 


\section{Sonuç}

Makalemizde Manas Destanındaki Çağdaş Türk lehçelerine özgün gramer özellikleri olarak tahmin edilen altı özelliğin şimdiki zaman $-\mathbf{X r}$ eki, şimdiki zaman - dX eki, men bağlaçı, sender zamiri, yönelme halinin I. ve II. şahıstaki magan, sagan çekimleri gibi beşi Kazak Türkçesi ile ilişkili olmaktadır. Bunun nedeni de Kazak ve Kırgızların aynı coğrafyada oturan, kaderleri bir akraba halklardan olmasıdır. Özellikle şimdiki zaman -Xr ekinin Kırgız ve Kazakların Kalmuklara yaptığı saldırılar anlatılırken çok söylenmesi manasçıların dil özelliklerini bilinçli olarak kullandığını göstermektedir. III. şahıs iyelik ekinden sonra kullanılan $+\mathbf{n X}$ yükleme hali ekini hem Kırgız Türkçesinin ağızlarına hem de bu ağızları etkileyen Özbek Türkçesine ait özellik olarak değerlendirmek mümkündür.

\section{Kaynakça}

ABDULDAEV, E. (1966). Kirglz Govorloru, Frunze.

BALAKEV M.B. vd., (1962). Sovremennıy Kazahskiy Yazık, Alma-Ata.

BURAN, A. ve ALKAYA, E. (1999). Çağdaş Türk Lehçeleri, Elazığ.

ÇOBANOĞLU, Ö. (2015). Türk Dünyası Epik Destan Geleneği, 4. Bask1, Ankara.

ECKMANN, J. (2003). Harezm, Kıpçak ve Çağatay Türkçesi Üzerine Araştırmalar, (yayına hazırlayan Prof. Dr. Osman Fikri Sertkaya), Ankara: TDK Yay.

KASAPOĞLU ÇENGEL, H. (2005). Kırgız Türkçesi Grameri - Ses ve Şekil BilgisiMetin-Çeviri-Dizin, Ankara: Akçağ Yayınları.

KAYDAROV, A.T., (1997). Kazahskiy Yazık, Yazıki Mira, Tyurkskiye Yazıki, Bişkek, s. $242-253$

KTLG: Karşılaştırmalı Türk Lehçeleri Grameri, I, -Fiil-, Basit Çekim, (Hakas Türkçesi, Arıkoğlu, Ekrem), 2006, Ankara.

KUDAYBERGENOV, S. vd. (1980). Kırgız Adabiy Tilinin Grammatikasl, I Bölüm, Fonetika cana Morfologiya, Frunze.

Musaev, Samar, \& diğer (Dü). (1995). Manas: baatırdık epos (S. Orozbakov) (Cilt I. kitap). Bişkek: Kırgız Bilimler Akademisi Yayınları.

Musaev, Samar, \& diğer (Dü). (1995). Manas: baatırdık epos (S. Orozbakov) (Cilt II. kitap). Bişkek: Kırgız Bilimler Akademisi Yayınları.

Musaev, Samar, \& diğer (Dü). (1995). Manas: baatırdık epos (S. Orozbakov) (Cilt III. kitap). Bişkek: Kırgız Bilimler Akademisi Yayınları.

Musaev, Samar, \& diğer (Dü). (1997). Manas: baatırdık epos (S. Orozbakov) (Cilt IV. kitap). Bişkek: Kırgız Bilimler Akademisi Yayınları.

Musaev, Samar, \& diğer (Dü). (2006). Manas: baatırdık epos (S. Orozbakov) (Cilt V. kitap). Bişkek: Kırgız Bilimler Akademisi Yayınları.

Musaev, Samar, \& diğer (Dü). (2014). Manas: baatırdık epos (S. Orozbakov) (Cilt VII. kitap). Bişkek: Kırgız Bilimler Akademisi Yayınları.

Musaev, Samar, \& diğer (Dü). (2014). Manas: baatırdık epos (S. Orozbakov) (Cilt VIII. ve IX. kitaplar). Bişkek: Kırgız Bilimler Akademisi Yayınları.

ORUZBAEVA, B. O. (2004). Kırgız Tilinin Tarıhın Tüzüüdö 'Manas' Eposunun Tili Negizgi Bulaktardın Biri. Kırgız Tililimi, II Tom, Bişkek, s. 165-167. 
RAKIMBEK UULU, M. (2010). 'Manas' Dastanındagl Arhaizm Sözdör (Cusup Mamaydın Varyantı Boyunça). Yayımlanmamış Doktora Tezi, Bişkek: KTMÜ.

ŞARŞENBEK UULU, T. (2014). Manas Eposundagı Dialektizmder (S.Orozbakovdun Varyantı Boyunça), V. Uluslararası Genç Türkologlar Sempozyumu (25-27 Nisan, 2012) Bildirileri (Haz.: N. Useev, C. Buyar), s. 45-70.

TENIŞEV E. R. $v d$., (2002). Sravnitel'no-İstoriçeskaya Grammatika Tyurkskih Yazıkov. Regiyonal'nıye Rekonstruktsii. Moskova.

USEEV, N. (2016a). Manas Destanı'nda 'Türkü Til' Kavramı. Türk Dünyası Dil ve Edebiyat Dergisi, Bahar 2016, S. 41, s. 203-223.

USEEV, N. (2016b). Manas Destanı'nda Türk Kelimesi ve Ağaç, Koyun/Koç Kültleri, TEKE Uluslararası Türkçe Edebiyat Kültür Eğitim Dergisi, 5 (4), s. 1611-1626.

USEEV, N. (2017). Manas (Semetey) Destanı'nda Geçen Türk Kelimesi ve KahramanAt-Silah Bütünlüğü, Uluslararası Türkçe Edebiyat Kültür Eğitim Dergisi, 6 (1), s. 52-64. 